\title{
Right atrial mass: Thrombus, myxoma, or cardiac papillary fibroelastoma?
}

\author{
Attilio A. Lotto, MD, MRCSI, ${ }^{a}$ Ursula M. Earl, MRCPath, FRCP, ${ }^{\text {b }}$ and W. Andrew Owens, MD, FRCS (CTh), ${ }^{a}$ Middlesbrough, \\ United Kingdom
}

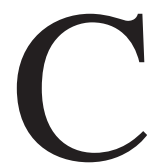

ardiac papillary fibroelastoma is a rare benign tumor most often found arising from valvular endocardium. ${ }^{1}$ A nonvalvular location is rare, and a right atrial position is extremely rare. ${ }^{2}$ On the other hand, a mass in the right atrium is more likely to represent a mobilized deep venous thrombus temporarily lodged in the right atrium ${ }^{3}$ or an atrial myxoma. ${ }^{1}$

\section{Clinical Summary}

We present the case of a 60-year-old woman who was referred for increasing shortness of breath during the preceding 2 years. Among other investigations, she underwent an echocardiogram, which revealed a dilated right atrium with a $2.5-\mathrm{cm}$ mass attached to the atrial free wall. This was interpreted as a thrombus, and the anticoagulant therapy (warfarin sodium) was started. At her 2-month follow-up, another echocardiogram showed no regression of the mass size. The patient was then referred to our center for a transesophageal echocardiogram, which showed the presence of a $2 \times 2.2-\mathrm{cm}$ mass attached with a stalk to the atrial free wall, a finding compatible with an atrial myxoma (Figure 1). As part of further investigations, the patient underwent a coronary angiogram, which demonstrated a $70 \%$ lesion in the mid left anterior descending coronary artery. She was then referred to our attention for excision of the right atrial tumor and coronary artery bypass grafting.

The operation was conducted with cardiopulmonary bypass, cannulation of the right femoral vein and superior vena cava, and normothermia. After institution of total cardiopulmonary bypass, the right atrium was opened. A 3-cm, gelatinous, thinly fronded mass was found attached to the pectinate muscles of the atrial free wall for approximately $1 \mathrm{~cm}$ with a short stalk base. Removal of the mass was performed with excision of a $2-\mathrm{cm}$ disk around the stalk (Figure 2), and direct closure of the right atrium was achieved. A left internal thoracic artery-left anterior descending coronary artery bypass graft was then performed. The patient recovered fully from the operation and was discharged home after

From the Departments of Cardiothoracic Surgery and Pathology, James Cook University Hospital, Middlesbrough, United Kingdom.

Received for publication Feb 27, 2006; accepted for publication March 15, 2006.

Address for reprints: W. Andrew Owens, MD, FRCS (CTh), Department of Cardiothoracic Surgery, James Cook University Hospital, Marton Rd, Middlesbrough TS4 3BW, United Kingdom(E-mail: Andrew.Owens@ stees. nhs.uk).

J Thorac Cardiovasc Surg 2006;132:159-60

$0022-5223 / \$ 32.00$

Copyright () 2006 by The American Association for Thoracic Surgery

doi:10.1016/j.jtcvs.2006.03.038

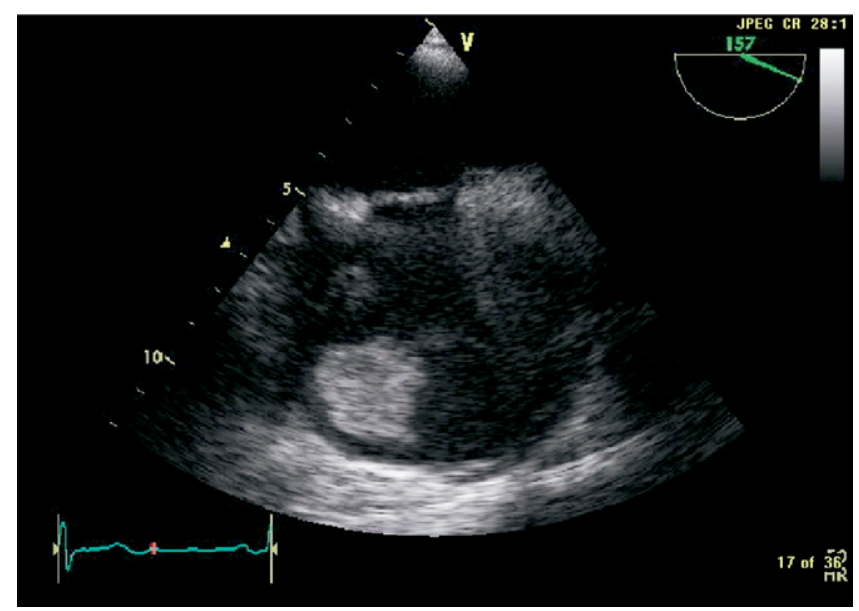

Figure 1. Transesophageal echocardiogram showing presence of mass attached with short stalk to right atrial free wall.

7 days. At 6 weeks of follow-up she is well, and her shortness of breath has substantially decreased.

Histologic examination of the tumor showed the presence of numerous avascular papillary fronds covered by a single layer of endothelial cells. This finding was compatible with papillary fibroelastoma.

\section{Discussion}

The presence of a right atrial mass in a patient with persistent respiratory symptoms is likely to represent a thrombus in transit from a deep venous compartment to the pulmonary arteries. ${ }^{3}$ When considering a differential diagnosis, however, acquired conditions such as tumors need to be taken into account. ${ }^{4}$ In particular, atrial myxomas are the most common cardiac tumors; although typically of the left atrium, in a substantial proportion of patients they may arise from the right atrium. ${ }^{5}$

In our case an initial transthoracic echocardiogram showed the presence of a right atrial mass that did not dissolve after 2 months of anticoagulation with warfarin sodium. The subsequent transesophageal echocardiogram revealed the presence of a small stalk that anchored the mass to the atrial appendage. This anatomic feature, along with the persistence of the mass after 2 months of anticoagulation, made the mass more likely to be an atrial myxoma. After surgical removal, the tumor was found to be a papillary fibroelastoma. Among the various types of cardiac tumors that could grow in this location, papillary fibroelastoma is the least likely. In fact, cardiac papillary fibroelastomas are most often found arising from valvular endocardium. ${ }^{1}$ In a large, comprehensive analysis of more 


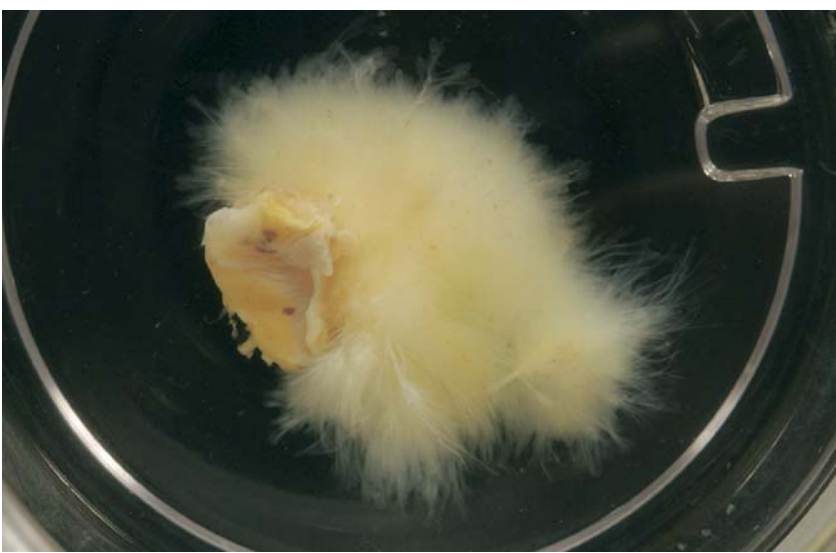

Figure 2. Papillary fibroelastoma excised with $2-\mathrm{cm}$ disk around stalk.

725 cases, in $84 \%$ of the cases the valvular surface was the predominant location of the tumor. ${ }^{2}$ Nonvalvular location is rare, and just 2 cases have been reported to involve the right atrium. ${ }^{6}$
This is the first report of a cardiac papillary fibroelastoma originating from pectinate muscles of the right atrial free wall.

\section{Conclusion}

Right atrial cardiac papillary fibroelastoma is an extremely rare finding. Only 2 cases have been previously reported in the literature. This is the first report of such a tumor attached to the pectinate muscles of the right atrial free wall.

\section{References}

1. Edwards FH, Hale D, Cohen A, Thompson L, Pezzella AT, Virmani R. Primary cardiac valve tumors. Ann Thorac Surg. 1991;52:1127-31.

2. Gowda RM, Khan IA, Nair CK, Mehta NJ, Vasavada BC, Sacchi TJ. Cardiac papillary fibroelastoma: a comprehensive analysis of 725 cases. Am Heart J. 2003;146:404-10.

3. Chartier L, Béra J, Delomez M, Asseman P, Beregi JP, Bauchart J, et al Free-floating thrombi in the right heart: diagnosis, management, and prognostic indexes in 38 consecutive patients. Circulation. 1999;99: 2779-83.

4. Panidis IP, Kotler MN, Mintz GS, Ross J. Clinical and echocardiographic features of right atrial masses. Am Heart J. 1984:107:745-58.

5. Reynen K. Cardiac myxomas. N Engl J Med. 1995;333:1610-7.

6. Schiller AL, Schantz A. Papillary endocardial excrescence of the right atrium: report of two cases. Am J Clin Pathol. 1970;53:617-21.

\section{Accessory mitral valve causing left ventricular outflow tract obstruction and mitral insufficiency}

Hiroshi Tanaka, MD, Kenji Okada, MD, Teruo Yamshita, MD, Keitaro Nakagiri, MD, Masamichi Matsumori, MD, and Yutaka Okita, MD, Kobe, Japan

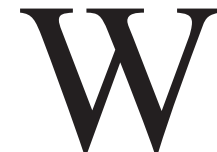

e report a case of accessory mitral valve that caused both left ventricular outflow tract (LVOT) obstruction and mitral insufficiency. This was treated surgically with excision of the accessory mitral valve, septal myectomy, and mitral annuloplasty. This is a rare case in which the accessory mitral valve caused both LVOT obstruction and mitral insufficiency describing the detail of the pathology.

\footnotetext{
Kobe University Hospital, Department of Cardiovascular, Thoracic, and Pediatric Surgery, Kobe, Japan.

Received for publication Jan 15, 2006; accepted for publication Jan 20, 2006.

Address for reprints: Hiroshi Tanaka, MD, Kobe University Hospital, Department of Cardiovascular, Thoracic, and Pediatric Surgery, 7-5-2, Kusunoki-cho, Chuo-ku, Kobe, Japan (E-mail: hirot@ams.odn.ne.jp).

J Thorac Cardiovasc Surg 2006;132:160-1

$0022-5223 / \$ 32.00$

Copyright $\odot 2006$ by The American Association for Thoracic Surgery doi:10.1016/j.jtcvs.2006.01.062
}

\section{Clinical Summary}

A 65-year-old man was referred to us for the diagnosis of moderate aortic insufficiency, moderate mitral insufficiency, and an abnormal structure in the LVOT. The electrocardiogram showed left ventricular hypertrophy and frequent ventricular arrhythmias. Transesophageal echocardiography demonstrated subaortic obstruction of the LVOT (Figure 1) (moderate aortic insufficiency, septal hypertrophy, and moderate mitral insufficiency), which was supposed to be caused by a cleft in the anterior mitral leaflet. The mean pressure gradient across the LVOT was $43 \mathrm{~mm} \mathrm{Hg}$.

At surgery, the aortic valve was tricuspid, with a large fenestration at the left coronary cusp-right coronary cusp commissure portion. There was an abnormal structure in the LVOT that looked like mitral leaflet tissue originating from the anterior mitral leaflet. This structure had chordae tendineae-like structures attached to the left ventricular surface of the anterior mitral leaflet and had interconnection to the chordae tendineae. When hooked by its free edge, the structure was opened like a parachute and occluded the LVOT. Simultaneously, the anterior mitral leaflet was retracted into the LVOT. No clefts were found in the anterior mitral leaflet. The structure was excised completely, and septal myectomy was performed. The left atrium was opened, and the mitral valve was seen to be almost normal, with a mild friction lesion of the anterior 